\title{
A pilot evaluation of mindfulness-based cognitive therapy for people with
}

\section{Jane Simpson ${ }^{1}$, Fiona Eccles ${ }^{1}$, Alistair Smith ${ }^{1}$, Siofra Peeren ${ }^{2}$, Dawn Rogers ${ }^{2}$,}

Zara Skitt ${ }^{2}$, Rachael Theed ${ }^{1}$, and David Craufurd ${ }^{2}$

${ }^{1}$ Division of Health Research, Faculty of Health and Medicine, Lancaster University, Lancaster, LA1 4YT, UK

${ }^{2}$ Division of Evolution and Genomic Sciences, Faculty of Biology, Medicine and Health, University of Manchester and Manchester Centre for Genomic Medicine, Central Manchester University Hospitals NHS Foundation Trust, Manchester, M13 9WL, UK

\section{Background \& aims}

Many people with the Huntington's disease (HD) gene experience low mood, anxiety and other psychological difficulties (e.g., Craufurd \& Snowden, 2014). Medication can help with these difficulties to some extent, but it is not always effective nor the preferred option. Psychological interventions may provide an alternative or additional way of alleviating distress.

Mindfulness based therapies have been shown to be successful in alleviating distress in a variety of populations (Khoury et al., 2013). Small benefits have been found for those with chronic health conditions (Bohlmeijer et al., 2010) including other neurological conditions such as Parkinson's disease (Fiztpatrick et al., 2010; Pickut et al., 2015).

We are conducting a pilot trial to see if mindfulness-based cognitive therapy (MBCT; Segal et al., 2013), is an acceptable and useful way of alleviating distress for people who have the HD gene and are pre-symptomatic or at an early disease stage.

\section{Methods}

10 pre-manifest HD gene carriers ( 6 females; 4 males; age range 24-64 years) completed an 8 week course of MBCT. The course, led by an experienced mindfulness teacher, consisted of weekly 2 hour sessions and up to an hour of home practice every day.

Measures of anxiety, depression, stress and mindfulness were administered pre- and post-course and at 3 months. Qualitative data about participants experiences were gathered via semi-structured interview.

We are currently recruiting for a second course and aim to run this in Autumn/ Winter 2016.

\section{Participants' experiences}

\section{"The classes, [...] they were really good. They were helpful"}

"Each lesson I was learning something new about yourself a bit and about how your mind works"

"It was empowering and uplifting [...] it just has been so wonderful for me" "Since I've been doing the mindfulness I wake up in the morning and it has changed a lot. I mean, my thoughts are calmer. HD is there but it's kind of softer and more at the edge of my brain not right at the front of my face. And I don't feel as terrified of it."

\section{Results}

Interview data suggested participants found the course acceptable and perceived it to be beneficial for their wellbeing.
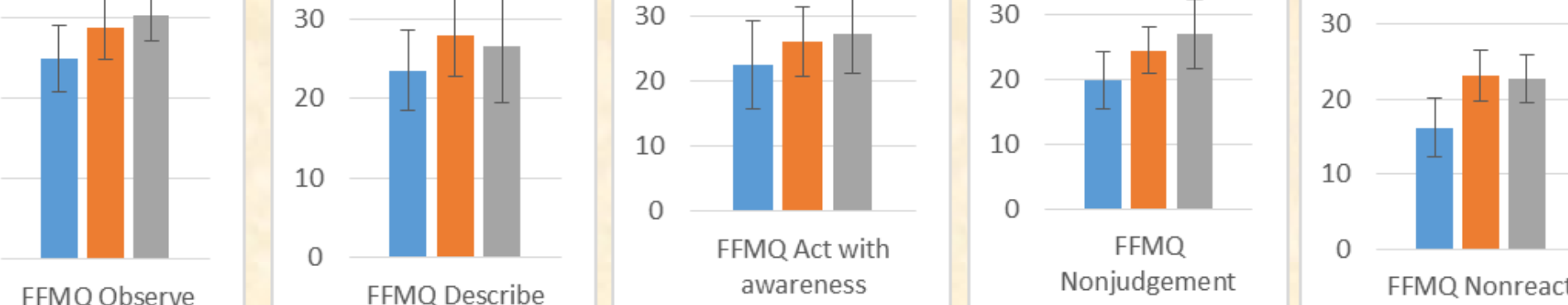

Although a very small sample size, analyses indicate that participants' mindfulness skills increased over the course and were maintained at 3 months, with small decreases in anxiety and stress (depression levels were low at baseline and remained unchanged).

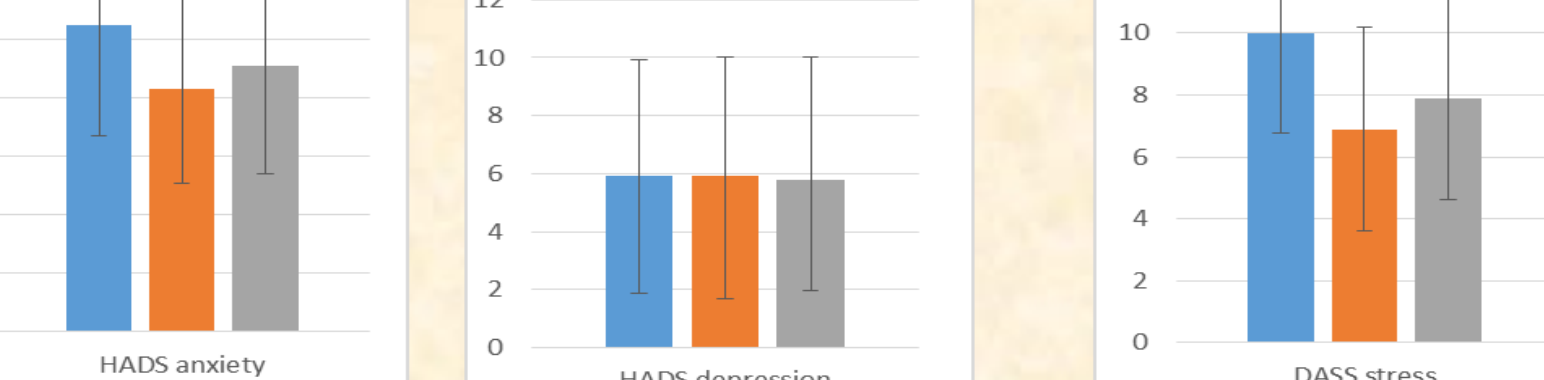

\section{Discussion}

- MBCT appears to be an acceptable psychological approach for some premanifest individuals with the HD gene.

- Early results indicate that learning mindfulness is possible and can be beneficial.

- A larger sample is needed to show if it can significantly reduce psychological distress and would benefit from including more individuals with raised depression at baseline to enable changes in depression to be detected.

- Participant feedback suggests committing to an 8 week course is difficult for many people with the HD gene and alternative methods of delivery may need to be considered.

\section{References}

Bohlmeijer E, Prenger R, Taal E, Cuijpers P. The effects of mindfulness-based stress reduction therapy on mental health of adults with a chronic medical disease: A meta-analysis. J. 6):539-544.

J editors. Huntington's disease. 4th ed. Oxford: Oxford University Press; 2014. p 36-65. izpatrick $L$, Simpson J, Smith A. A qualitative analysis of mindfulness-based cognitive therapy (MBCT) in Parkinson's disease. Psychol. Psychother.-Theory Res. Pract. 2010;83(2):179-192

Khoury B, Lecomte T, Fortin G, Masse M, Therien P, Bouchard V, Chapleau M-A, Paquin K, Hofmann SG. Mindfulness-based therapy: A comprehensive meta-analysis. Clin. Psychol. Rev. 2013;33(6):763-771.

ickut B, Vanneste S, Hirsch MA, Van Hecke W, Kerckhofs E, Mariën P, Parizel PM, Crosiers D, Cras P. Mindfulness Training among Individuals with Parkinson's Disease: Neurobehavioral Effects.

: York: New York : Guilford Press; 2013.

Funded by a seed grant from the European Huntington's Disease Network. 